\title{
Differential regulation of nuclear and mitochondrial Bcl-2 in $T$ cell apoptosis
}

\author{
Dagmar Scheel-Toellner $\cdot$ Karim Raza $\cdot$ Lakhvir Assi · Darrell Pilling \\ Emma J. Ross · Wing Yiu Lee - S. John Curnow - Christopher D. Buckley • \\ Arne N. Akbar · Janet M. Lord · Mike Salmon
}

Published online: 23 October 2007

(C) Springer Science+Business Media, LLC 2007

\begin{abstract}
Activated T cells require anti-apoptotic cytokines for their survival. The anti-apoptotic effects of these factors are mediated by their influence on the balance of expression and localisation of pro- and anti-apoptotic members of the Bcl-2 family. Among the anti-apoptotic Bcl-2 family members, the expression level of Bcl-2 itself and its interaction with the pro-apoptotic protein Bim are now regarded as crucial for the regulation of survival in activated $\mathrm{T}$ cells. We studied the changes in Bcl-2 levels and its subcellular distribution in relation to mitochondrial depolarisation and caspase activation in survival factor deprived $\mathrm{T}$ cells. Intriguingly, the total $\mathrm{Bcl}-2$ level appeared to remain stable, even after caspase 3 activation indicated entry into the execution phase of apoptosis. However, cell fractionation experiments showed that while the dominant nuclear pool of Bcl-2 remained stable during apoptosis, the level of the smaller mitochondrial pool was rapidly downregulated. Signals induced by anti-apoptotic cytokines continuously replenish the mitochondrial pool, but nuclear Bcl-2 is independent of such signals. Mitochondrial Bcl-2 is lost rapidly by a caspase independent mechanism in the absence of
\end{abstract}

D. Scheel-Toellner and K. Raza have contributed equally to this study.

D. Scheel-Toellner $(\bowtie) \cdot$ K. Raza · L. Assi - D. Pilling .

E. J. Ross - W. Y. Lee · S. J. Curnow · C. D. Buckley ·

J. M. Lord · M. Salmon

MRC Centre of Immune Regulation, Division of Immunity and Infection, Institute of Biomedical Research, University of Birmingham, Birmingham B15 2TT, UK

e-mail: d.scheel@bham.ac.uk

\section{A. N. Akbar}

Department of Immunology and Molecular Pathology, Royal Free and University College Medical School, London WIT 4JF, UK survival factors, in contrast only a small proportion of the nuclear pool of Bcl-2 is lost during the execution phase and this loss is a caspase dependent process. We conclude that these two intracellular pools of Bcl-2 are regulated through different mechanisms and only the cytokine-mediated regulation of the mitochondrial pool is relevant to the control of the initiation of apoptosis.

Keywords Bcl-2 - Cytokines · Survival - Lymphocytes . Programmed cell death

\section{Introduction}

In the absence of external survival signals activated $\mathrm{T}$ cells enter apoptosis spontaneously. Anti-apoptotic signals include cytokines such as Type I interferons, IL-6 and those that signal through the common $\gamma$ chain (IL-2, IL-4, IL-7, IL-15 and IL-21) [1-7]. Several lines of evidence suggest that commitment to apoptosis under conditions of survival signal deprivation occurs in mitochondria [8-10]. Loss of mitochondrial membrane potential is associated with the release of pro-apoptotic factors including cytochrome c. This complexes with pro-caspase 9, ATP and the adapter protein APAF to form the apoptosome, which cleaves and activates executioner caspases [11]. Members of the Bcl-2 family of proteins regulate entry to apoptosis by regulating mitochondrial membrane potential and cytochrome c release [12-20]. This family includes proapoptotic molecules such as Bax, Bad, Bak, Bim, Puma, Noxa and Bid, and anti-apoptotic molecules, such as Bcl- $\mathrm{x}_{\mathrm{L}}, \mathrm{A} 1, \mathrm{Mcl}-1$ and Bcl-2 itself, which are upregulated by anti-apoptotic cytokines [21]. One current model suggests that the main role of $\mathrm{Bcl}-2$ lies in counterbalancing the pro-apoptotic signal induced by the cooperation of Bim 
with either Bax or Bak [22, 23]. Alternative explanations for the pro-apoptotic role of Bim involve mechanisms that are independent of binding Bax and Bak at the mitochondrial level [24]. All of these models however assume a key role for the interaction of Bim with Bcl-2. Bim and Bcl-2 appear to from stable complexes directly on the mitochondrial surface [25]. Loss of $\mathrm{Bcl}-2$ rather than an increase in the level of Bim levels is thought to be the triggering process $[25,26]$.

Cleavage of $\mathrm{Bcl}-2$ and $\mathrm{Bcl}-\mathrm{x}$ by caspases during the execution phase of apoptosis can generate cleavage products that facilitate apoptosis $[27,28]$. Reduced transcription of anti-apoptotic Bcl-2 family members is thought to be a trigger for apoptosis [29-34]. However, previous reports have suggested that the level of $\mathrm{Bcl}-2$ is very stable in murine $\mathrm{T}$ cells during cytokine deprivation-induced apoptosis $[35,36]$. In these reports, the total level of Bcl-2 in whole cell lysates was studied, but the location of Bcl-2 within the cell was not. Several groups have shown that Bcl-2 is found in sites other than the mitochondria, with a large proportion in the nucleus [37-40]. In the present study, we report changes in the intracellular location of Bcl-2 during the entry of activated $\mathrm{T}$ cells into apoptosis following cytokine withdrawal. The smaller mitochondrial pool of Bcl-2 is lost early, during commitment to apoptosis, in a caspase independent manner. It is this mitochondrial pool that is actively regulated by anti-apoptotic cytokines. In contrast, the larger nuclear pool is actively cleaved by caspases during the execution phase of apoptosis and is not involved in the initiation of this process.

\section{Materials and methods}

$\mathrm{T}$ cell culture and stimulation

Non-transformed $\mathrm{CD} 4^{+\mathrm{ve}} \mathrm{T}$ cell lines were generated by phytohaemagglutinin (PHA) stimulation of $\mathrm{CD} 4^{+v e} \mathrm{~T}$ cells isolated by negative selection from the peripheral blood of normal individuals as described previously [3]. $\mathrm{T}$ cells were cultured in complete medium [RPMI 1640 containing $10 \%$ heat inactivated fetal calf serum, $10 \mathrm{mM}$ HEPES buffer, glutamine $(2 \mathrm{mM})$, penicillin $(100 \mathrm{U} / \mathrm{ml})$, streptomycin $(100 \mu \mathrm{g} / \mathrm{ml})$ (all Sigma, UK)] at $37^{\circ} \mathrm{C}$ in a humidified incubator with an atmosphere of $5 \% \mathrm{CO}_{2}$. They were stimulated every 14 days with $9 \mu \mathrm{g} / \mathrm{ml}$ PHA (PHA HA15, Murex Biotech, Dartford, UK) and $50 \mathrm{U} / \mathrm{ml}$ recombinant IL-2 (Chiron, Harefield, UK) in the presence of $10 \%$ autologous EBV transformed LCL irradiated with 4,000 rads using a ${ }^{60} \mathrm{Co}$ source (Dept. of Physics, University of Birmingham). $\mathrm{T}$ cells were maintained with additional IL-2 $(50 \mathrm{U} / \mathrm{ml})$ every 2 days. T cell lines were used for experimental analysis 7 days after re-stimulation with PHA and 2 days after the last addition of IL-2. Prior to use, $\mathrm{T}$ cells were subjected to ficoll density centrifugation to maximise the proportion of viable cells (Ficoll-Paque ${ }^{\mathrm{TM}}$ Plus, Amersham Biosciences, Uppsala, Sweden).

Cytokine deprivation induced apoptosis

T cells were cultured at a density of $1 \times 10^{6}$ cells $/ \mathrm{ml}$ in 6 , 24 or 96 well flat bottomed plates in RPMI 1640 supplemented with $1 \%$ BSA, $10 \mathrm{mM}$ HEPES buffer, glutamine $(2 \mathrm{mM})$, penicillin $(100 \mathrm{U} / \mathrm{ml})$, and streptomycin $(100 \mu \mathrm{g} /$ $\mathrm{ml})$. The kinetics of apoptosis in 6, 24 and 96 well plates were identical (data not shown). Cells were harvested at stated time points. In certain experiments $\mathrm{T}$ cells were cultured in medium containing $50 \mathrm{U} / \mathrm{ml}$ IL-2, $10 \mu \mathrm{g} / \mathrm{ml}$ cycloheximide (Sigma, UK) or $100 \mu$ M ZVAD.fmk (Caspase inhibitor 1, Calbiochem).

Flow cytometric $\mathrm{T}$ cell survival assays

The percentage of apoptotic cells was determined by flowcytometry following either 3,3'-dihexyloxacarbocyanine iodide $\left(\mathrm{DiOC}_{6}(3)\right)$ [41] (Molecular Probes, Oregon, USA) staining, or intracellular staining for active caspase 3 , as described below. Mitochondrial integrity was measured by a flow cytometric method based on the ability of intact mitochondria to take up and retain fluorochromes. Cultured $\mathrm{T}$ cells were loaded with $20 \mathrm{ng} / \mathrm{ml} \mathrm{DiOC}_{6}(3)$ for $30 \mathrm{~min}$ at $37^{\circ} \mathrm{C}$. Cells were then washed in phosphate buffered saline (PBS), resuspended and analysed on a Coulter Epics XL flow cytometer. The detected cells were gated on the basis of the forward scatter and sideward scatter signal. Gated cells were then analysed for their level of fluorescence emission at $525 \mathrm{~nm}$ after excitiation at $488 \mathrm{~nm}$, indicating accumulation of $\mathrm{DiOC}_{6}(3)$ in the intact mitochondria. The percentage of $\mathrm{DiOC}_{6}(3)$-low cells of the total cell population analysed was expressed as $\%$ apoptotic cells. The staining was compared with staining with JC-1 (Molecular Probes) and yielded identical results in split samples (data not shown). For the flow cytometric analysis of caspase 3 activation, T cells were fixed and permeabilised using PermeaFix ${ }^{\mathrm{TM}}$ solution (Ortho Diagnostic Systems Inc., New Jersey, USA) for $45 \mathrm{~min}$ at room temperature. The fixed cells were washed twice in PBS, before incubation in 50\% fetal calf serum in RPMI to reduce non-specific antibody binding. Cells were then stained with an affinity purified rabbit anti-active caspase 3 antibody (BD PharMingen, California, USA) or normal rabbit immunoglobulin fraction (Dako, Denmark) as a negative control. These were detected with fluorescein (FITC) labelled goat anti-rabbit IgG antiserum (Southern Biotech, Birmingham, AL, USA). 
Immunofluorescence staining for mitochondrial membrane potential and $\mathrm{Bcl}-2$

$\mathrm{T}$ cells were incubated with $50 \mathrm{nM}$ MitoTracker Red CMXRos (Molecular Probes, Oregon, USA) for $30 \mathrm{~min}$ at $37^{\circ} \mathrm{C}$, washed once in $2 \%$ bovine serum albumin (BSA) (Sigma, UK) in PBS, resuspended in 2\% BSA in PBS and transferred onto a glass slide in a cytocentrifuge (Shandon, USA). Cells were fixed and permeabilised in acetone (Fisher Scientific UK Ltd, UK). Blocking was performed with $20 \%$ goat serum (Dako, Denmark), $0.2 \%$ fish skin gelatin (Sigma, UK), $0.5 \%$ casein (Fisher Scientific UK Ltd, UK) in PBS for $60 \mathrm{~min}$. Monoclonal mouse antihuman Bcl-2 antibody, clone 124, (Dako, Denmark) or mouse IgG1 negative control (Dako, Denmark) were applied for $60 \mathrm{~min}$ followed by 2 washes with PBS. Biotin conjugated goat anti-mouse IgG was applied for $30 \mathrm{~min}$ followed by 2 washes with PBS. Primary and secondary antibodies were diluted in $20 \%$ goat serum, $0.2 \%$ fish skin gelatin, $0.5 \%$ casein in PBS. FITC-conjugated streptavidin (Dako, Denmark) was applied for $30 \mathrm{~min}$ followed by 2 washes with PBS. The nuclei, were counterstained with 4',6-diamidino-2-phenylindole dihydrochloride (DAPI) at 40 ng/ml. Samples were mounted (AF1, Citifluor Ltd., UK) and visualised using a confocal immunofluorescence microscope (Zeiss LSM 510 based on a Zeiss Axiophot M100). A $63 \times$ water immersion lens was used and a $2 \times$ zoom added in the Zeiss LSM software. The images were processed in PaintShop pro version 5 to enhance contrast and brightness.

\section{Caspase-3 activity assay}

Cell pellets were made at appropriate time points and frozen in liquid nitrogen. Cells were thawed, resuspended in modified hypotonic cell lysis buffer (25 mM HEPES $\mathrm{pH}$ 7.5, $5 \mathrm{mM} \mathrm{MgCl}_{2}, 2 \mathrm{mM}$ PMSF, $10 \mu \mathrm{g} / \mathrm{ml}$ Pepstatin A, $10 \mu \mathrm{g} / \mathrm{ml}$ AEBSF $2 \mathrm{mM}$, EDTA $1 \mathrm{mM}$, Bestatin $130 \mu \mathrm{M}$, E-64 $14 \mu \mathrm{M}$, Leupeptin $1 \mu \mathrm{M}$, Aprotinin $0.3 \mu \mathrm{M}$ (Sigma, UK)) and lysed by taking them through 3 freeze thaw cycles. Samples were centrifuged at $16,000 \mathrm{~g}$ at $4{ }^{\circ} \mathrm{C}$ for $20 \mathrm{~min}$ and the supernatant removed. Protein quantification was performed using the bicinchoninic acid (BCA) protein assay kit (Pierce Chemical Company, USA) according to manufacturer's instructions. The level of protein in each sample was standardised by adding appropriate amounts of modified lysis buffer ( $5 \mathrm{mM}$ DTT and $5 \mathrm{mM}$ EDTA). Caspase 3 activity was measured with the CaspACE ${ }^{\mathrm{TM}}$ fluorimetric assay system (Promega, Wisconsin, USA) according to manufacturer's instructions using the fluorescent labelled caspase 3 substrate ac-DEVD-AMC on a Perkin-Elmer fluorimeter with Ascent fluoroscan software.
${ }^{3} \mathrm{H}$ leucine protein synthesis assay

T cells were incubated in flat bottomed 96 well plates in the presence of $0.4 \mu \mathrm{Ci}^{3} \mathrm{H}$ leucine (Amersham, UK) in a total volume of $100 \mu \mathrm{l}$. At appropriate time points, $100 \mu \mathrm{l}$ of $10 \%$ trichloroacetic acid (w/v) (Fisher Scientific UK Ltd., UK) was added and the cells incubated on ice for $1 \mathrm{~h}$. Cells were harvested onto filter paper and the radioactivity measured using a beta plate reader.

\section{Cell fractionation}

Cells were incubated in hypotonic swelling buffer $(20 \mathrm{mM}$ Tris pH 7.4, 2 mM $\mathrm{MgCl}_{2}, 5$ mM EDTA, $1 \mathrm{mM}$ Sodium Vanadate, $10 \mu \mathrm{g} / \mathrm{ml}$ each of pepstatin, leupeptin and aprotinin and $2 \mathrm{mM} \mathrm{AEBSF}$ ) for $30 \mathrm{~min}$. This was followed by homogenisation with a Dounce homogenizer. Cellular disruption was controlled by microscopic observation of Trypan blue stained cells. The homogenate was fractionated by centrifugation for $1,000 \mathrm{~g}$ for $4 \mathrm{~min}$ (nuclei), $10 \mathrm{~min}$ for $10,000 \mathrm{~g}$ (mitochondria, heavy membranes), and $30 \mathrm{~min}$ at $100,000 \mathrm{~g}$ (to separate the cytosol from the plasma membrane and light membrane fraction). The nuclear, mitochondrial and plasma membrane pellets were resuspended in SDS PAGE sample buffer. The cytosolic fraction was mixed with 0.1 Vol 10× SDS PAGE buffer. Samples were heated for $5 \mathrm{~min}$ at $95^{\circ} \mathrm{C}$ and stored for western blotting.

\section{Western blotting}

For the majority of experiments western blots samples were loaded on a cell equivalent basis. In the experiments shown in Figs. $1 \mathrm{~b}$ and $2 \mathrm{a}, 5 \times 10^{6} \mathrm{~T}$ cells were lysed in SDS PAGE sample buffer and heated for $5 \mathrm{~min}$ to $95^{\circ} \mathrm{C}$. The equivalent of $0.5 \times 10^{6}$ cells per lane were loaded on SDS-PAGE gels. For the experiments shown in Figs. 3a, $4 \mathrm{a}$ and $5,20 \times 10^{6}$ cells per sample were fractionated and the equivalent of the nuclear, mitochondrial cytosolic and membraneous content of $2 \times 10^{6}$ cells were loaded onto western blots per lane. For the experiments shown in Fig. $3 b$ the SDS-PAGE gels were loaded with equal protein amounts. For this purpose, the cell pellets of the mitochondrial fractions were resuspend in lysis buffer containing $0.26 \mathrm{M}$ Tris pH6.8, 2.6\% SDS and 1\% protease inhibitor cocktail (Sigma, St Louis, MO, USA). The protein concentration was assayed using the BCA assay according to the manufacturer's instructions (Pierce, Rockford, IL, USA). BSA in a range of concentrations from $4-0.003 \mathrm{mg} / \mathrm{ml}$ in lysis buffer was used as a standard. After protein quantification $27 \mu \mathrm{l}$ of a solution containing $80 \%$ Glycerol 
and $20 \%$ Mercaptoethanol and $5 \mathrm{mg} / \mathrm{ml}$ Bromophenol blue were added per $100 \mu \mathrm{l}$ lysate. Samples were heated for $5 \mathrm{~min}$ at $95^{\circ} \mathrm{C}$. $5 \mu \mathrm{g}$ protein was loaded onto SDS-PAGE gels per lane. Total cellular proteins separated by SDSPAGE and transferred to PVDF membrane (Flowgen) using a wet blotting system (Bio rad). Blots were blocked in $4 \%$ nonfat milk powder and probed with antibodies to caspase 3 (Rabbit anti-caspase 3, Pharmingen), Bcl-2 (BD Pharmingen) or Actin (Sigma) or VDAC-1 (Abcam, Cambridge, UK).

\section{Results}

Activated $\mathrm{T}$ cells rapidly enter apoptosis if deprived of survival-inducing cytokines.

A

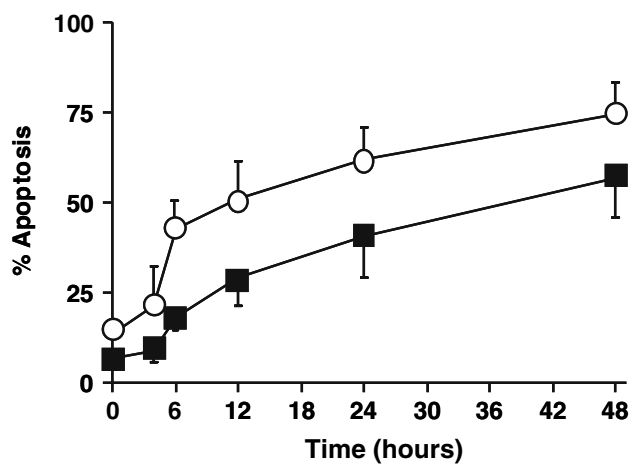

B

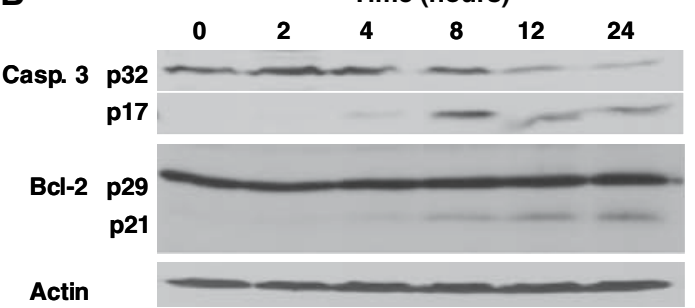

Fig. 1 Kinetics of caspase 3 activation, mitochondrial depolarisation and Bcl-2 levels in survival factor deprived activated T cells. (a) Activated $\mathrm{T}$ cells were cultured in the absence of survival factors for $0,4,6,12,24$ and $48 \mathrm{~h}$. At these time points cells were stained with an antibody specific for activated caspase 3 (closed symbols). The fraction of cells with low mitochondrial membrane potential was measured by staining with $\mathrm{DiOC}_{6}(3)$ (open symbols). The data shown represent the mean and $\mathrm{SD}$ of 4 independent experiments. (b) Changes in the levels of expression of proteins regulating apoptosis in $\mathrm{T}$ cells deprived of survival factors were determined by western blotting. Activated T cells were cultured in the absence of survival factors for $0,2,4,8,12$ and $24 \mathrm{~h}$. The cells were lysed and subjected to western blotting analysis for Bcl-2 and caspase 3. Blots for actin were run to control for equal loading. Activation of caspase 3 occurs early in cytokine deprivation mediated apoptosis of $\mathrm{T}$ cells, while Bcl-2 levels appeared to remain stable throughout the experiment. The $21 \mathrm{kD}$ cleavage product of $\mathrm{Bcl}-2$ was detected concurrently with the activation of caspase 3. The experiment shown is one representative of 3 independent experiments performed

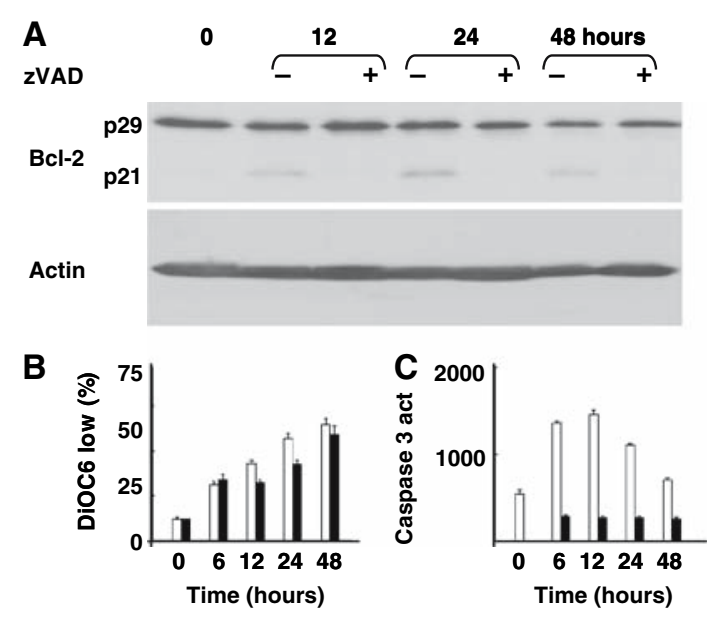

Fig. 2 The influence of caspase activity on the level of Bcl-2 in T cells deprived of survival factors. (a) Activated T cells were cultured for 12, 24 and $48 \mathrm{~h}$ in the presence and absence of ZVAD.fmk, an irreversible broad range inhibitor of caspases. Cells were lysed and analysed for the loss of whole length Bcl-2 and the appearance of the $21 \mathrm{kD}$ cleaved form by western blotting. Blots were also probed for actin to control for equal cell input. The appearance of the cleaved $21 \mathrm{kD}$ form of Bcl-2 was inhibited by ZVAD.fmk. (b) Activated T cells were cultured for $6,12,24$ and $48 \mathrm{~h}$ in the presence (closed bars) and absence (empty bars) of ZVAD.fmk, an irreversible broad range inhibitor of caspases. The inhibition of caspase activity led to a minor and transient delay of mitochondrial depolarisation. The percentage of cells with depolarised mitochondria was determined by staining cells with $\mathrm{DiOC}_{6}(3)$ and measurement of the fraction of cell population able to retain this dye (3). (c) The efficiency of ZVAD.fmk-mediated inhibition of caspase 3 in this cellular system was determined by measure of the enzymatic activity of caspase 3 in an assay measuring the cleavage of a fluorogenic substrate in cells cultured without (empty bars) or with ZVAD.fmk (filled bars). Activity of caspase 3 was reliably inhibited by ZVAD.fmk. The results shown here are means and SD of triplicates of one experiment representative for 3 independent similar experiments performed

As shown in Fig. 1a, our experimental conditions allowed a rapid and reproducible initiation of apoptosis in $\mathrm{CD} 4^{+\mathrm{ve}}$ activated $\mathrm{T}$ cells following survival factor deprivation. We analysed the time course of activation of caspase 3 in relation to the changes of Bcl-2 expression in this experimental system by western blotting (Fig. 1b). In parallel experiments mitochondrial depolarisation and caspase 3 activation were assessed by flow cytometry (Fig. 1a). Activation of caspase 3 and mitochondrial depolarisation showed a maximal rate of change between $4 \mathrm{~h}$ and $12 \mathrm{~h}$. This corresponded well with the appearance of the cleaved form of caspase 3 and loss of the pro-form of caspase 3. The active fragment of caspase 3 was detected as a faint band at $4 \mathrm{~h}$ and as a strong band at $8 \mathrm{~h}$. Members of the Bcl-2 family are thought to regulate $\mathrm{T}$ cell apoptosis at the mitochondrial level. Induction of expression of $\mathrm{Bcl}-2$ by cytokines signalling through the shared $\gamma$-chain of the IL-2 receptor is an important regulator of $\mathrm{T}$ cell survival. The changes in Bcl-2 expression 
A
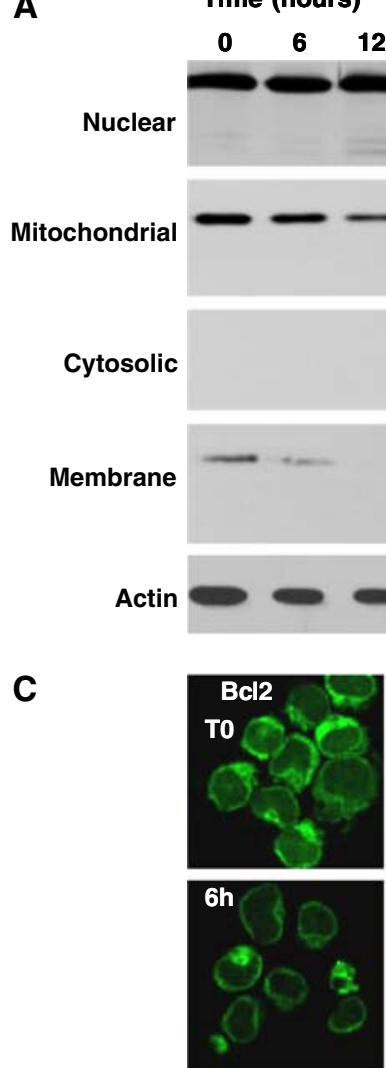
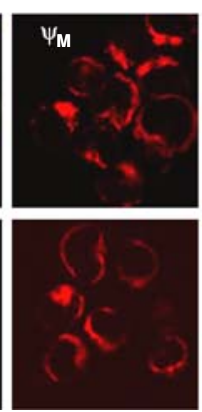

B

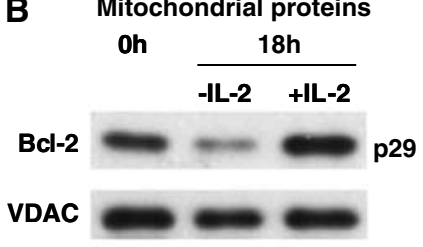

Fig. 3 Influence of cytokine deprivation on the subcellular localisation of Bcl-2. (a) Activated $\mathrm{T}$ cells were cultured in the absence of survival factors for $0,6,12$ and $24 \mathrm{~h}$. The cells were fractionated into nuclear, mitochondrial, cytoplasmic and plasma membrane fractions by centrifugation and equivalents of fractions derived from $2 \times 10^{6}$ cells per lane were probed for Bcl-2 by western blotting. The cytoplasmic fractions were probed for actin to control for equal cell input. The largest fraction of $\mathrm{Bcl}-2$ was found to be localised in the nuclei. Most of the remaining $\mathrm{Bcl}-2$ was detected in the mitochondrial fraction, and a very small amount in the plasma membrane fraction. While the nuclear fraction remained stable throughout the experiment, there was a continuous loss of Bcl-2 from the mitochondrial fraction, which was evident from the $6 \mathrm{~h}$ time point. One experiment shown as representative of 3 similar experiments performed. (b) To control if these changes in Bcl-2 levels were specific for mitochondria and not caused by general loss of mitochondrial protein, these experiments were repeated with $5 \mu \mathrm{g}$ protein per lane. Loading controls used here were specific for mitochondria (VDAC-1). (c) Activated $\mathrm{T}$ cells were cultured in the absence of survival factors for 0, 6, 12 and 24 h. $20 \mathrm{~min}$ before harvesting, the live cells were incubated in Mitotracker CR red ${ }^{\mathrm{TM}}$ to label mitochondria with an intact mitochondrial membrane potential red. Cells were then spun onto slides using a cytospin centrifuge and stained for Bcl-2 (green). Analysis by confocal microscopy revealed staining for Bcl-2 both on the mitochondria as well as on the nuclear envelope at time 0 . At $6 \mathrm{~h}$ and at the later time points the mitochondrial staining was found to be less intense, while the nuclear staining remained stable. Images shown here are representative of 4 independent experiments following survival factor withdrawal were investigated by western blotting. Intriguingly, whilst low levels of the cleavage product of Bcl-2 were detectable after $8 \mathrm{~h}$, levels of intact Bcl-2 remained largely unchanged over time. These experiments suggested that a significant loss of Bcl-2 did not precede mitochondrial depolarization and caspase 3 activation.

The caspase inhibitor ZVAD.fmk was used to test if the appearance of the short form of Bcl-2 was caspasedependent. As shown in Fig. 2a the appearance of the short form of Bcl-2, within $12 \mathrm{~h}$ of cytokine withdrawal, was efficiently blocked by the caspase inhibitor. Loss of the full-length form of Bcl-2 was only apparent at the latest time point $(48 \mathrm{~h})$ and the caspase inhibitor had little effect on this. The effect of the caspase inhibitor on mitochondrial depolarisation is shown in Fig. 2b. There was a minor delay of mitochondrial depolarisation at the earlier time points, but by $48 \mathrm{~h}$ no effect of caspase inhibition on mitochondrial depolarisation was observed. The efficiency of caspase 3 inhibition under these culture conditions was tested by assessing the enzymatic activity of caspase 3 in lysates of the $T$ cells. Figure $2 \mathrm{c}$ shows that at all time points investigated, ZVAD.fmk effectively blocked caspase 3 activation. These data are consistent with a model of $\mathrm{T}$ cell apoptosis in which detectable loss of overall $\mathrm{Bcl}-2$ does not play a key role in the regulation of mitochondrial integrity, because it is lost only after mitochondrial depolarisation has taken place. At this stage the cells have fully 

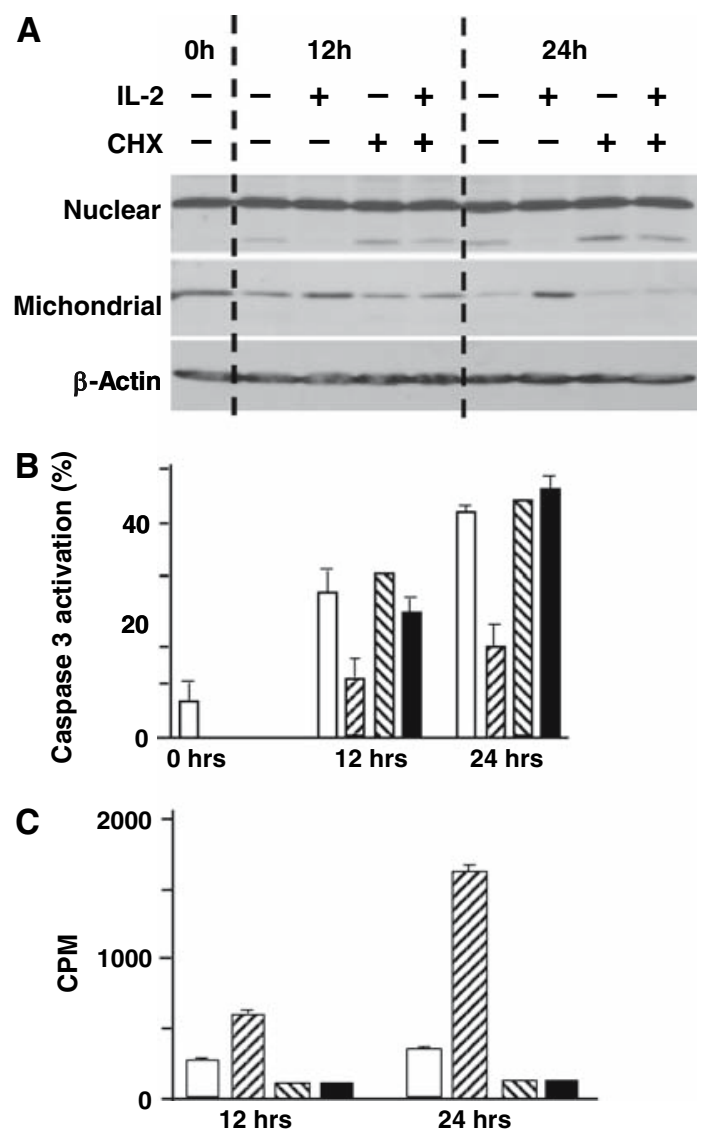

Fig. 4 The mitochondrial, but not the nuclear pool of Bcl-2 is dependent upon continuous protein synthesis. (a) Activated $\mathrm{T}$ cells were cultured for 0,12 and $24 \mathrm{~h}$ cells in the absence and presence of IL-2 and cycloheximide. Cells were fractionated and mitochondrial and nuclear fractions were probed for Bcl-2 by western blotting. The cytoplasmic fractions were probed for actin to control for equal cell input. The experiment shown is one representative of 3 independent experiments performed. (b) The effect of cycloheximide on $\mathrm{T}$ cell apoptosis in this experimental system was determined by measuring the percentage of cells with activated caspase 3 in samples taken from the cultures used for the fractionation experiments. Clear bars indicate cells cultured in medium alone, upwards hatched bars cells cultured with IL-2, downwards hatched bars cells cultured with cycloheximide and filled bars indicate cells cultured in both cycloheximide and IL-2. The results shown here represent the mean and SD of three experiments performed. (c) The efficiency of cycloheximide mediated inhibition of protein synthesis in this cellular system was determined by measuring the incorporation of ${ }^{3} \mathrm{H}$ leucine. Clear bars indicate cells cultured in medium alone, upwards hatched bars cells cultured with IL-2, downwards hatched bars cells cultured with cycloheximide and filled bars indicate cells cultured in both cycloheximide and IL-2. The results shown here are means and SD of triplicates representative for three experiments performed

activated caspase 3 and have entered the execution phase of apoptosis.

The anti-apoptotic role of Bcl-2 may be restricted to specific sites within the cell. To test this hypothesis, T cells were fractionated by centrifugation at different $\mathrm{g} /$ forces into the nuclear, cytosolic, light membrane and heavy membrane fractions. The heavy membrane fraction

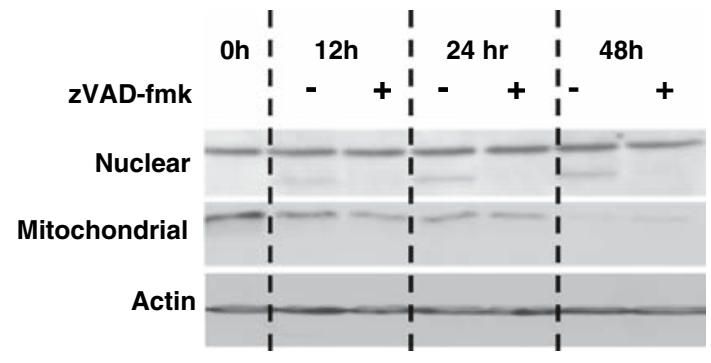

Fig. 5 The role of caspase activity in the regulation of Bcl-2 levels in nuclei and mitochondria. To answer the question if loss of Bcl-2 from the mitochondria or nuclear pool was upstream or downstream of caspase activation, we incubated $\mathrm{T}$ cells in the presence and absence of ZVAD.fmk for 12, 24 and $48 \mathrm{~h}$, fractionated them and probed the nuclear and mitochondrial fractions for Bcl-2. The cytoplasmic fractions were probed for actin to control for equal cell input. While the levels of full length $\mathrm{Bcl}-2$ in the nuclear fraction were not obviously affected within the time frame of the experiment, the appearance of the cleaved $21 \mathrm{kD}$ fragment of Bcl-2 was blocked by ZVAD.fmk. The loss of Bcl-2 from the mitochondrial fraction was not affected by ZVAD.fmk, suggesting that this is an event that occurs upstream of caspase activation. The experiment shown is one representative of 3 independent experiments performed

contained most of the mitochondrial membrane, while the light membrane fractions contained the plasma membrane. The efficiency of fractionation was tested by western blot detection of marker proteins characteristic of the respective fractions. Lamin B, a constituent of the nuclear envelope was exclusively found in the nuclear fraction. Actin was found in the cytosolic fraction, and TIM 23 a mitochondrial membrane transporter protein was detected in the heavy membrane, or mitochondrial fraction. Pan-cadherin, a molecule expressed on the plasma membrane was found in the light membrane fraction (data not shown). The majority of the cellular $\mathrm{Bcl}-2$ was detected in the nuclear fraction (ca. $60 \%$, by densitometric analysis of western blots). The mitochondrial fraction contained about $30 \%$ of the cellular Bcl-2 and a minor amount was detected in the cytosolic fraction. In the experiment shown in Fig. 3a, T cells were fractionated after deprivation of survival factors. Intriguingly, the cleaved fragment of Bcl-2 was only detected in the nuclear fraction, a consistent finding throughout all fractionation experiments performed in this study. This cleavage product appears to be very susceptible to proteolytic degradation as it appeared as a single band in the experiments in which we directly lysed the cell pellets in SDS-PAGE running buffer, while multiple bands became apparent in the samples after the fractionation process.

A striking observation was that while the level of full length nuclear Bcl-2 remained stable for the duration of the experiment, the level of mitochondrial Bcl-2 decreased at an early stage following cytokine deprivation. This loss of Bcl-2 from the mitochondrial fraction was clearly seen as early as $6 \mathrm{~h}$ and therefore coincided with the sharp increase in mitochondrial depolarisation and caspase 3 activation. 
These observations suggest that while no obvious change occurred in the total level of Bcl-2 within the cell (Fig. 1b) there was an early loss of Bcl-2 from the mitochondrial fraction, which was masked by the stability of the larger nuclear pool. While the SDS-PAGE gels had been loaded on the basis of cell equivalents in the initial experiments, we repeated the experiment by loading equal amounts of protein. We used an antibody to the Voltage Dependent Anion Channel (VDAC-1), which is localised in the outer mitochondrial membrane, control for equal loading of mitochondrial proteins. The result of these experiments is shown in Fig. 3b. The loss of Bcl-2 from the mitochondrial fraction, is again apparent under these conditions. Presence of IL-2 in the cultures counteracted the loss of Bcl-2 from the mitochondria.

Similar results were obtained using immunofluorescence (Fig. 3c). Initially, Bcl-2 was seen on the nuclear envelope and the mitochondria. By $6 \mathrm{~h}$, loss of Bcl-2 from the mitochondria was observed, but staining of the nuclear envelope remained stable.

These data suggest that two separate pools of Bcl-2 in T cells are regulated at different stages of apoptosis.

The mechanism of this regulation was investigated in subsequent experiments. Mitochondrial $\mathrm{Bcl}-2$ appeared to be less stable than that in the nuclear pool. To test whether the mitochondrial pool was more dependent on continuous synthesis of Bcl-2 than the nuclear fraction, $\mathrm{T}$ cells were cultured in the presence of IL-2 and cycloheximide. Cell fractionation experiments showed that Bcl-2 in the nuclear fraction remained stable under all conditions tested in the experiments, but that the mitochondrial fraction maintained stable Bcl-2 levels only in the presence of IL-2 and the absence of cycloheximide (Fig. 4a). These results suggest that the mitochondrial pool of Bcl-2 depends upon constant replenishment by induction of de novo synthesis of Bcl-2 by anti-apoptotic cytokines. However, the stable Bcl-2 expression in the nucleus was independent of protein synthesis over the time period studied. While cycloheximide did inhibit the survival effect of IL-2 it did not appear to have an added toxic effect above that of IL-2 deprivation within these experiments (Fig. 4b), but protein synthesis was effectively inhibited (Fig. 4c).

These data indicate that the mitochondrial pool of Bcl-2 is critically dependent on anti-apoptotic cytokines in the microenvironment and support a role for mitochondrial Bcl-2 in the regulation of $\mathrm{T}$ cell apoptosis by cytokines.

The caspase dependent cleavage fragment of Bcl-2 was restricted to the nuclear fraction (Fig. 3a). This suggested that only the loss of nuclear Bcl-2 was mediated by caspase dependent cleavage. $\mathrm{T}$ cells were incubated with ZVAD.fmk and fractionated at specific time points. The short form of Bcl-2 was absent from the samples treated with ZVAD.fmk, but the loss from the mitochondrial fraction was unaffected by inhibition of caspases (Fig. 5). These data suggest that the loss of mitochondrial $\mathrm{Bcl}-2$ is caspase independent. Therefore we conclude that the two intracellular pools of Bcl-2 are regulated by at least two different mechanisms at different stages in the apoptotic pathway.

\section{Discussion}

During the resolution of an immune response, loss of extracellular survival signals leads to a dramatic reduction in activated $\mathrm{T}$ cell numbers by apoptosis. Mitochondria are widely regarded as the regulators of this apoptotic pathway [8-10]. Their role in apoptosis is controlled by pro- and anti-apoptotic proteins of the Bcl-2 family [12-20]. Many anti-apoptotic cytokines upregulate the transcription of genes for anti-apoptotic Bcl-2 family members [2]. In the absence of these survival signals, activated $\mathrm{T}$ cells are programmed to enter apoptosis. There is very strong evidence suggesting a role for Bcl-2 itself in the regulation of $\mathrm{T}$ cell apoptosis [2, 42, 43]. However, Broome et al. have shown that Bcl-2 levels remain stable after the induction of apoptosis in activated murine $\mathrm{T}$ cells and are not downregulated even late in apoptosis $[35,36]$. Our data brings these observations together by demonstrating two spatially distinct pools of Bcl-2 within T cells that are differentially regulated and are lost at different stages of apoptosis through distinct mechanisms. The survival signal IL-2 maintains mitochondrial Bcl-2 levels in a translationally dependent manner. Withdrawal of IL-2 leads to loss of mitochondrial Bcl-2. This loss is independent of caspase activation. In contrast, the larger nuclear pool remains stable until caspase 3 is fully activated and a small proportion is then cleaved in a caspase-dependent manner. If only the total cellular levels of Bcl-2 are assayed, the stability of the larger nuclear pool can mask the loss of the smaller mitochondrial pool at an early stage of apoptosis. We conclude from these observations that only the smaller cytokine-regulated mitochondrial pool of $\mathrm{Bcl}-2$ is relevant to the initiation of the apoptotic pathway and that measuring the total cellular level of Bcl-2 is less informative. Bcl-2 degradation has been shown to be caused by targeting of Bcl-2 to the protesomal system by ubiquitinylation [44]. Ubiquitinylation appears to be regulated by at least two mechanisms. Phosphorylation of Bcl2 at MAPK target sites protects it from ubiquitinylation and subsequent degradation [45]. In a more recent report endothelial nitric oxide synthase, which is also expressed by $\mathrm{T}$ cells, was shown to generate nitric oxide which S-nitrosylates $\mathrm{Bcl}-2$ and prevents its ubiquitinylation $[46,47]$. It is not clear which of these mechanisms plays a dominant role in the regulation of $\mathrm{Bcl}-2$ levels in $\mathrm{T}$ cells, 
but it is possible that $\mathrm{Bcl}-2$ in the nuclear compartment is less accessible to ubiquitinylation or one of the mechanisms regulating it.

Bcl-2 is known to be a target for caspase 3. Intriguingly, we only found the caspase dependent cleaved fragment of Bcl-2 in the nuclear fraction. The majority of active caspase 3 is cytosolic [11], and Bcl-2 is localised on the leaflet of the mitochondrial membrane facing the cytosol [39] so it was surprising that no cleaved Bcl-2 was detected in the cytosol or the mitochondria. This may reflect highly efficient degradation of mitochondrial Bcl-2 before caspase 3 activation. The cleaved fragment of $\mathrm{Bcl}-2$ has been reported to have a pro-apoptotic function [28]. If transfected into cells, it localises to the mitochondria and forms ion channel like structures that mediate cytochrome $\mathrm{c}$ release [28]. However, the role of this potentially proapoptotic Bcl-2 fragments in spontaneous $\mathrm{T}$ cell apoptosis has not been previously addressed. In the present study, the generation of the cleaved fragment was entirely dependent upon caspase activation and no cleaved Bcl-2 was detectable in the mitochondrial fraction. This data does not support the contention that cleaved Bcl-2 controls mitochondrial polarity during the initiation of spontaneous apoptosis [28].

While it is difficult to assess the functional significance of a stable nuclear pool of Bcl-2, a tightly controlled mitochondrial pool is likely to be necessary for the regulation of mitochondrial stability and the apoptotic pathway. The role of Bcl-2 on the nuclear envelope and the function of the cleaved fragment at this site during the execution phase of apoptosis remain unclear. Nuclear Bcl-2 may mediate the anti-proliferative effects associated with this protein [48]. Such a role would fit with its stability in the early stages of apoptosis. During the execution phase of apoptosis nuclear Bcl-2 is cleaved in a caspase-dependant manner to the pro-apoptotic form. It is therefore possible that in the nucleus, the cleaved fragment of $\mathrm{Bcl}-2$ plays a role in the later phases of the apoptotic pathway, but not in regulating entry to apoptosis. Bim, a pro-apoptotic member of the Bcl-2 family has recently been shown to be involved in the initiation of survival factor deprivation induced apoptosis [49]. Even though Bim can bind to components of the dynein motor system, in T cells most of the cellular Bim is bound to the mitochondria, where it directly interacts with Bcl-2 [25]. The pro-apoptotic effect of Bim in T cells can be balanced by over-expression of Bcl-2 [49]. These data support the previously described anti-apoptotic effect of Bcl-2 in the regulation of $\mathrm{T}$ cell numbers in vivo. Bcl-2 deficient mice are severely lymphopenic and their lymphocytes show increased susceptibility to apoptosis [30-33]. Over-expression of Bcl-2 under the vav-promotor results in increased $\mathrm{T}$ cell numbers [50]. The regulation of $\mathrm{T}$ cell survival by anti-apoptotic cytokines is fundamental in maintaining $\mathrm{T}$ cell numbers during inflammatory responses and in restoring a homeostatic balance during the resolution of inflammation. Dysregulation of this process contributes to the pathology of diseases such as rheumatoid arthritis.

\section{Conclusion}

We have characterised the regulation of Bcl-2 levels in $\mathrm{T}$ cell apoptosis induced by cytokine withdrawal. The mitochondrial pool of $\mathrm{Bcl}-2$ is modulated prior to the commitment to apoptosis, while the nuclear pool remains stable. Only the mitochondrial pool is regulated by the presence of anti-apoptotic cytokines. Consequently, we suggest that the role of anti-apoptotic cytokines in inhibiting $\mathrm{T}$ cell apoptosis by $\mathrm{Bcl}-2$ induction is limited to the up-regulation of the mitochondrial pool of Bcl-2.

Acknowledgements The authors would like to thank D. Hardie and H. Chahal for their technical assistance. This work was supported by a programme grant from the Arthritis Research Campaign. DS-T is supported by an ARC non-clinical Career Development Fellowship (Grants no. S0652, S0710, R0576).

\section{References}

1. Duke RC, Cohen JJ (1986) IL-2 addiction: withdrawal of growth factor activates a suicide program in dependent $\mathrm{T}$ cells. Lymphokine Res 5:289-299

2. Akbar AN, Borthwick NJ, Wickremasinghe RG et al (1996) Interleukin-2 receptor common gamma-chain signaling cytokines regulate activated $\mathrm{T}$ cell apoptosis in response to growth factor withdrawal: selective induction of anti-apoptotic (bcl-2, bcl-xL) but not pro- apoptotic (bax, bcl-xS) gene expression. Eur J Immunol 26:294-299

3. Pilling D, Akbar AN, Girdlestone J et al (1999) Interferon-beta mediates stromal cell rescue of $\mathrm{T}$ cells from apoptosis. Eur $\mathrm{J}$ Immunol 29:1041-1050

4. Kuroda K, Yagi J, Imanishi K et al (1996) Implantation of IL-2-containing osmotic pump prolongs the survival of superantigen-reactive $\mathrm{T}$ cells expanded in mice injected with bacterial superantigen. J Immunol 157:1422-1431

5. Vella AT, Dow S, Potter TA, Kappler J, Marrack P (1998) Cytokine-induced survival of activated $\mathrm{T}$ cells in vitro and in vivo. Proc Natl Acad Sci USA 95:3810-3815

6. Kaneko S, Suzuki N, Koizumi H, Yamamoto S, Sakane T (1997) Rescue by cytokines of apoptotic cell death induced by IL-2 deprivation of human antigen-specific $\mathrm{T}$ cell clones. Clin Exp Immunol 109:185-193

7. Curnow SJ, Scheel-Toellner D, Jenkinson W et al (2004) Inhibition of $\mathrm{T}$ cell apoptosis in the aqueous humor of patients with uveitis by IL-6/soluble IL-6 receptor trans-signaling. J Immunol 173:5290-5297

8. Kroemer G, Reed JC (2000) Mitochondrial control of cell death. Nat Med 6:513-519

9. Green DR, Reed JC (1998) Mitochondria and apoptosis. Science 281:1309-1312

10. Reed JC (1997) Cytochrome c: can't live with it-can't live without it. Cell 91:559-562 
11. Thornberry NA, Lazebnik Y (1998) Caspases: enemies within. Science 281:1312-1316

12. Strasser A, Pellegrini M (2004) T-lymphocyte death during shutdown of an immune response. Trends Immunol 25:610-615

13. Reed JC (1997) Double identity for proteins of the Bcl-2 family. Nature 387:773-776

14. Chao DT, Korsmeyer SJ (1998) BCL-2 family: regulators of cell death. Annu Rev Immunol 16:395-419

15. Hockenbery DM, Oltvai ZN, Yin XM, Milliman CL, Korsmeyer SJ (1993) Bcl-2 functions in an antioxidant pathway to prevent apoptosis. Cell 75:241-251

16. Hockenbery D, Nunez G, Milliman C, Schreiber RD, Korsmeyer SJ (1990) Bcl-2 is an inner mitochondrial membrane protein that blocks programmed cell death. Nature 348:334-336

17. Kluck RM, Bossy-Wetzel E, Green DR, Newmeyer DD (1997) The release of cytochrome $\mathrm{c}$ from mitochondria: a primary site for Bcl-2 regulation of apoptosis. Science 275:1132-1136

18. O'Reilly LA, Huang DC, Strasser A (1996) The cell death inhibitor Bcl-2 and its homologues influence control of cell cycle entry. EMBO J 15:6979-6990

19. Yang J, Liu X, Bhalla K et al (1997) Prevention of apoptosis by Bcl-2: release of cytochrome $\mathrm{c}$ from mitochondria blocked. Science 275:1129-1132

20. Shimizu S, Narita M, Tsujimoto Y (1999) Bcl-2 family proteins regulate the release of apoptogenic cytochrome $\mathrm{c}$ by the mitochondrial channel VDAC. Nature 399:483-487

21. Cory S, Adams JM (2002) The Bcl2 family: regulators of the cellular life-or-death switch. Nat Rev Cancer 2:647-656

22. Zong WX, Lindsten T, Ross AJ, MacGregor GR, Thompson CB (2001) BH3-only proteins that bind pro-survival Bcl-2 family members fail to induce apoptosis in the absence of Bax and Bak. Genes Dev 15:1481-1486

23. Cheng EH, Wei MC, Weiler S et al (2001) BCL-2, BCL-X(L) sequester $\mathrm{BH} 3$ domain-only molecules preventing $\mathrm{BAX}$ - and BAK-mediated mitochondrial apoptosis. Mol Cell 8:705-711

24. Willis SN, Fletcher JI, Kaufmann T et al (2007) Apoptosis initiated when $\mathrm{BH} 3$ ligands engage multiple $\mathrm{Bcl}-2$ homologs, not Bax or Bak. Science 315:856-859

25. Zhu Y, Swanson BJ, Wang M et al (2004) Constitutive association of the proapoptotic protein Bim with Bcl-2-related proteins on mitochondria in T cells. Proc Natl Acad Sci USA 101:76817686

26. Green DR, Kroemer G (2004) The pathophysiology of mitochondrial cell death. Science 305:626-629

27. Cheng EH, Kirsch DG, Clem RJ et al (1997) Conversion of Bcl-2 to a Bax-like death effector by caspases. Science 278:1966-1968

28. Kirsch DG, Doseff A, Chau BN et al (1999) Caspase-3dependent cleavage of $\mathrm{Bcl}-2$ promotes release of cytochrome $\mathrm{c}$. J Biol Chem 274:21155-21161

29. Mueller DL, Seiffert S, Fang W, Behrens TW (1996) Differential regulation of bcl-2 and bcl-x by $\mathrm{CD} 3, \mathrm{CD} 28$, and the IL-2 receptor in cloned $\mathrm{CD} 4+$ helper $\mathrm{T}$ cells. A model for the longterm survival of memory cells. J Immunol 156:1764-1771

30. Strasser A, Harris AW, Cory S (1991) bcl-2 transgene inhibits T cell death and perturbs thymic self-censorship. Cell 67:889-899

31. Deng G, Podack ER (1993) Suppression of apoptosis in a cytotoxic T-cell line by interleukin 2-mediated gene transcription and deregulated expression of the protooncogene bcl-2. Proc Natl Acad Sci USA 90:2189-2193

32. Nakayama K, Nakayama K, Negishi I, Kuida K, Sawa H, Loh DY (1994) Targeted disruption of Bcl-2 alpha beta in mice: occurrence of gray hair, polycystic kidney disease, and lymphocytopenia. Proc Natl Acad Sci USA 91:3700-3704
33. Nakayama K, Nakayama K, Negishi I et al (1993) Disappearance of the lymphoid system in Bcl-2 homozygous mutant chimeric mice. Science 261:1584-1588

34. Matsuzaki Y, Nakayama K, Nakayama K et al (1997) Role of bcl-2 in the development of lymphoid cells from the hematopoietic stem cell. Blood 89:853-862

35. Broome HE, Dargan CM, Krajewski S, Reed JC (1995) Expression of Bcl-2, Bcl-x, and Bax after T cell activation and IL-2 withdrawal. J Immunol 155:2311-2317

36. Broome HE, Dargan CM, Bessent EF, Krajewski S, Reed JC (1995) Apoptosis and Bcl-2 expression in cultured murine splenic $\mathrm{T}$ cells. Immunology 84:375-382

37. Krajewski S, Tanaka S, Takayama S, Schibler MJ, Fenton W, Reed JC (1993) Investigation of the subcellular distribution of the bcl-2 oncoprotein: residence in the nuclear envelope, endoplasmic reticulum, and outer mitochondrial membranes. Cancer Res 53:4701-4714

38. Akao Y, Otsuki Y, Kataoka S, Ito Y, Tsujimoto Y (1994) Multiple subcellular localization of bcl-2: detection in nuclear outer membrane, endoplasmic reticulum membrane, and mitochondrial membranes. Cancer Res 54:2468-2471

39. Lithgow T, van Driel R, Bertram JF, Strasser A (1994) The protein product of the oncogene bcl-2 is a component of the nuclear envelope, the endoplasmic reticulum, and the outer mitochondrial membrane. Cell Growth Differ 5:411-417

40. Motoyama S, Kitamura M, Saito S et al (1998) Bcl-2 is located predominantly in the inner membrane and crista of mitochondria in rat liver. Biochem Biophys Res Commun 249:628-636

41. Petit PX, O'Connor JE, Grunwald D, Brown SC (1990) Analysis of the membrane potential of rat- and mouse-liver mitochondria by flow cytometry and possible applications. Eur J Biochem 194:389-397

42. Akbar AN, Borthwick N, Salmon M et al (1993) The significance of low Bcl-2 expression by CD45RO T cells in normal individuals and patients with acute viral infections. The role of apoptosis in T cell memory. J Exp Med 178:427-438

43. Orteu CH, Poulter LW, Rustin MH, Sabin CA, Salmon M, Akbar AN (1998) The role of apoptosis in the resolution of T cellmediated cutaneous inflammation. J Immunol 161:1619-1629

44. Dimmeler S, Breitschopf K, Haendeler J, Zeiher AM (1999) Dephosphorylation targets Bcl-2 for ubiquitin-dependent degradation: a link between the apoptosome and the proteasome pathway. J Exp Med 189:1815-1822

45. Breitschopf K, Haendeler J, Malchow P, Zeiher AM, Dimmeler S (2000) Posttranslational modification of Bcl-2 facilitates its proteasome-dependent degradation: molecular characterization of the involved signaling pathway. Mol Cell Biol 20:1886-1896

46. Ibiza S, Victor VM, Bosca I et al (2006) Endothelial nitric oxide synthase regulates $\mathrm{T}$ cell receptor signaling at the immunological synapse. Immunity 24:753-765

47. Azad N, Vallyathan V, Wang L et al (2006) S-nitrosylation of Bcl-2 inhibits its ubiquitin-proteasomal degradation. A novel antiapoptotic mechanism that suppresses apoptosis. J Biol Chem 281:34124-34134

48. Vairo G, Innes KM, Adams JM (1996) Bcl-2 has a cell cycle inhibitory function separable from its enhancement of cell survival. Oncogene 13:1511-1519

49. Hildeman DA, Zhu Y, Mitchell TC et al (2002) Activated T cell death in vivo mediated by proapoptotic bcl-2 family member bim. Immunity 16:759-767

50. Ogilvy S, Metcalf D, Print CG, Bath ML, Harris AW, Adams JM (1999) Constitutive Bcl-2 expression throughout the hematopoietic compartment affects multiple lineages and enhances progenitor cell survival. Proc Natl Acad Sci USA 96:14943-14948 